\title{
Regular Article \\ Effects of psychoeducation for depression on help-seeking willingness: Biological attribution versus destigmatization
}

\author{
DER-YAN HAN, MS, ${ }^{1,2}$ SUE-HUEI CHEN, PhD, ${ }^{1}$ KWANG-KUO HWANG, $\mathrm{PhD}^{1}$ AND \\ HAI-LANG WEI, MD ${ }^{2}$ \\ ${ }^{1}$ Department of Psychology, National Taiwan University, Taipei and ${ }^{2}$ Department of Psychiatry, Taoyuan \\ Veterans Hospital, Taoyuan, Taiwan
}

\begin{abstract}
Existing literature shows that the level of biological attribution and stigma of depression influences willingness to seek help. However, no study has used experimental methods to explore the question whether increasing biological attribution and decreasing blameworthy attitude towards depression will enhance willingness to seek help. In so doing, 299 college students were randomly assigned to biological, destigmatization, combined, and control groups. The measures included the Biological Attribution Scale, Psychological Blame Scale, and Help-Seeking Willingness Scale. The data were analyzed by a $2 \times 2$ ANCovA (with or without biological attribution education $\times$ with or without destigmatization education) on willingness to seek professional help which was assessed 2 weeks later, with adjusting for help-seeking willingness at baseline. Results showed that biological education had a significant main effect to elevate help-seeking willingness, but destigmatization education did not. In addition, no interaction effect existed between the two independent variables. The authors suggested that biological education makes people legitimize depression as a disease entity, so that it would be a practical approach to increase people's motivation to solve their emotional afflictions, especially in societies that emphasize emotional constraints. In contrast, although destigmatization information reduces people's negative appraisals to the depressed individuals, it does not go a step further to increase people's motivation to seek professional help. Further studies are needed to clarify the mechanisms of educational effects.
\end{abstract}

Key words attribution, depression, help-seeking behavior, psychoeducation, stigma.

\section{INTRODUCTION}

Depression is poised to be one of the major diseases in the twenty-first century. The cross-national Global Burden of Disease study conducted by the World Health Organization concluded that depression is one of the most debilitating health problems in the world. ${ }^{1}$ Moreover, it is predicted that, by the year 2020, depression will account for $15 \%$ of the disease burden indexed by the extent of disability measured by number of work days lost and mortality associated with

Correspondence address: Sue-Huei Chen, PhD, Department of Psychology, National Taiwan University, 1, Sec. 4, Roosevelt Road, Taipei 106, Taiwan. Email: shchen@ntu.edu.tw

Received 16 November 2005; revised 2 March 2006; accepted 5 May 2006. non-communicable diseases. ${ }^{1}$ Apparently, the intervention of depression would be an important challenge to health-care providers in this century.

For past decades, accumulating empiric studies have proved that both pharmacotherapy and psychotherapy are effective to remedy depression. ${ }^{2,3}$ The most difficult problem in the intervention of depression, however, is that people who suffer from depression are reluctant to seek professional help. For example, a nationwide epidemiologic study in the USA showed that only $12 \%$ of depressed people sought help from mental health professionals. ${ }^{4}$ The acceptance of mental health professionals was even lower among Chinese people. According to a survey conducted in primary care, for example, only $3.5 \%$ Chinese Americans sought help from mental health professionals for their depressive symptoms. $^{5}$ 
Since the 1970s, researchers have noticed that Chinese and Japanese students underutilized mental health services. ${ }^{6-8}$ Further studies found that the less individualistic orientation, or the more acculturated to Asian cultures, the more negative attitude to seek professional help. ${ }^{9,10}$ These findings suggest that cultural factors may play a role in people's decision to seek help.

Furthermore, Ying found $57.5 \%$ of depressive Chinese women attributed depressive symptoms to psychological sources, and instead of seeking professional help, they tended to turn to themselves, family, and friends for assistance. In contrast, $30.0 \%$ of people holding a biological conceptualization were more likely to seek out professional help. ${ }^{11}$ A cultural comparative study also showed that, when comparing Caucasian-American students with Japanese-American students, the latter were more likely to attribute depression to weak mindedness, and, therefore, to resolve problems on their own or to seek help just from family members and friends. Differently, CaucasianAmerican students tended to attribute problems to diet or hereditary factors, and, therefore, to seek help from medical or mental health professionals. ${ }^{12}$

Based on the above-mentioned literature, the authors proposed a quasi-experimental study that when people attribute depression to biological factors, they are more willing to seek professional help. In contrast, when they attribute depression to personal negative traits, they feel more reluctant to seek professional assistance. Based on evidence, some studies supported this argument and showed an association between the attribution of depression and willingness to seek help. For example, college student studies showed that the tendency to attribute depression to genetic and biochemical factors positively correlated with willingness to seek professional help, ${ }^{13}$ while the tendency to attribute depression to one's own fault or responsibility negatively correlated with willingness to seek professional help. ${ }^{14}$

Past studies demonstrated the correlation between attribution and help-seeking. It would be more worthy to examine whether a causal relationship exists in order to implement effective preventive programs for depression at a community base. To the authors' knowledge, however, there is no study with a valid experimental design to prove a causal relationship existing between attribution and help-seeking tendency. The present study, therefore, aimed to explore the effects of changing attribution of depression on help-seeking willingness. More specifically, the authors used biological health education to increase people's attribution of depression to biological factors and destigmatization education to decrease blaming and negative appraisals of depression. The authors hypothesized that both an increase in biological attribution of depression and a decrease in the blameworthy attitude towards depression would elevate willingness to seek professional help. Last, the authors argued that, when both kinds of information were presented together, owing to the processes concerning increasing biological attribution as well as decreasing psychological blame, the effect would be greater than with only one kind of information.

\section{METHOD}

\section{Participants}

Participants for this study were drawn from the student body of three universities in northern Taiwan. The total number of participants was 299, including 144 undergraduates who completed the survey in order to fulfill course credit of introductory psychology, and 155 other students of the nursing, nutrition, Chinese literature, and Japanese language classes who were invited and received no credit for their participation. The average age was $20.3 \pm 2.18$ years (range, $18-36$ years). Of all, $73 \%$ were female and $31 \%$ had religious beliefs.

\section{Materials for experimental manipulations}

It has been demonstrated in an empiric study that evidence-based information did change people's attitude towards help-seeking willingness and appraisals of the effectiveness of psychotherapy. ${ }^{15}$ In the present study, paragraphs conveying either biological or destigmatization information were, therefore, designed based on existing evidences drawn from textbooks of Abnormal Psychology ${ }^{16}$ and General Psychiatry. ${ }^{17}$

Concerning biological attribution of depression, there were five paragraphs containing aspects about genes, neurotransmitters, endocrine systems, and physiological characteristics of depression. Two to three sources of evidence were used for each paragraph to explain the biological basis of major depression. Taking the aspect of the first paragraph for instance, the concordance rate for major depressive disorder in identical twins and first-degree relatives were illustrated to purposely emphasize its hereditability. In this biological education, the subjects were provided five short paragraphs to read sequentially and the process took about 5-10 min.

The aim of destigmatization education was to reduce the psychological blame for the depressed people. There were also five paragraphs containing aspects about stigmatization of depression commonly seen from social observations such as viewing the depressed 
people as lower in ability, having weaker willpower, being close-minded and reluctant to think positively, holding a lazy attitude towards improving themselves, and considering depression as a fault made by the depressed person. Each paragraph included 2-3 sources of evidence or statements elicited from psychological theories or clinical observations. For instance, concerning the aspect that those who are depressed are no less intelligent than non-depressed people, the authors used intelligence quotient scores as evidence and cited a study to prove that the depressed people had a more objective judgment than non-depressed counterparts. ${ }^{18}$ Similarly, in this destigmatization education, the five paragraphs were provided to the subjects to read sequentially and the process took about $5-10$ min as well.

\section{Measures}

\section{Extent of information acquisition}

Parallel to the aspects of biological and destigmatization education described above, the authors also designed two corresponding questionnaires, the Biological Attribution Scale (BAS) and Psychological Blame Scale (PBS), respectively. Each questionnaire consisted of five items on a 5-point Likert-type scale (i.e. from $1=$ strongly disagree to $5=$ strongly agree) to assess the extent that participants regard depression as a biological disease and that participants blame the depressed people, respectively.

The average score of the BAS was $3.4 \pm 0.73$, indicating that, for these undergraduates, the attribution of depression had a moderate tendency to biological sources. The Cronbach's alpha of the scale was 0.72 . The test-retest reliability with interval of 2 weeks was 0.74 , while taking the control group as the re-test sample $(n=64)$. An exploratory factor analysis was performed through the principle component method. According to the scree plot of factor loadings, one single factor was resulted with the criterion of eigenvalue exceeding 1 and accounting for $49.5 \%$ of the total variance.

The average score of the PBS was $3.0 \pm 0.66$, indicating that these undergraduates had a neutral attitude towards the depressed people. The Cronbach's alpha of the scale was 0.70 . The test-retest reliability with interval of 2 weeks was 0.76 , while taking the control group as the re-test sample. An exploratory factor analysis was performed through the principal component method. According to the scree plot of factor loadings, one single factor was found with the criterion of eigenvalue exceeding 1 and accounting for $49.3 \%$ of the total variance.

\section{Tendency of help-seeking willingness}

The Help-Seeking Willingness Scale (HSWS) was developed for this study to assess participants' willingness to seek help from professionals, provided that they are suffering from depression. Because some participants might not understand the content of depression, this scale started with an introduction described as follows: 'If I have depressive symptoms like a sad mood, diminished interest or pleasure, lack of activity, and irregular eating or sleeping, I would like to ...' The items asked to what extent whether they were willing to seek help from psychiatrists, physicians of family medicine, and counselors, to receive psychotherapy and clinical psychologists' advice, and simply to take medicine by doctor's advice. The 11-point Likert-type scale was from 0 (completely not willing) to 10 (completely willing).

The mean of the HSWS was $5.78 \pm 2.79$, indicating that these undergraduates had a positive tendency to seek help from professionals. The Cronbach's alpha of the scale was 0.93 and the test-retest reliability with interval of 2 weeks was 0.78 , taking control group as re-test sample. An exploratory factor analysis was performed through the principle component method. According to the scree plot of factor loadings, one single factor was found with the criterion of eigenvalue exceeding 1 and accounting for $74.6 \%$ of the total variance.

\section{Procedure and experimental manipulation}

The data were collected during November and December 2004. At the first wave of group tests, 299 students participated in the experiment. After signing the informed consents, participants were asked to fill out demographic information including gender, age, and religion as well as the HSWS, BAS, and PBS. The HSWS was used to evaluate if different health education programs make different changes on the willingness to seek professional help. The purposes of the BAS and PBS were used to check if the experimental manipulations changed people's attribution of depression.

To explore the cause-effect association between attribution and help-seeking tendency, all the participants were randomly assigned into one of the four groups: biological education group $(n=75)$, destigmatization group $(n=76)$, combined group $(n=72)$, and control group $(n=76)$. Participants in the biological education group read five short paragraphs explaining the biological etiology and related information on depression. Participants in the destigmatization group read another five short paragraphs to reduce the psychological blameworthy attitude toward the depressed 
people. Participants in the combined group read the above 10 paragraphs, and those in the control group did not read any information.

After 2 weeks, all participants were asked to complete the HSWS, BAS, and PBS again. Overall, 252 $(84.3 \%)$ participants completed these three scales in the second wave of data collection, including 64 of the biological group (85.3\%), 56 of the destigmatization group (73.7\%), 61 of the combined group (84.7\%), and 62 of the control group (81.6\%). After completing the two waves of surveys, participants were thanked and fully debriefed by a sheet of paper describing the purpose of the study, and the multiple explanatory models of depressive disorders were emphasized.

\section{Data analysis}

In a preliminary examination of the demographic variables between the subject distributions of the two waves of data collection, the authors found a significant difference of gender percentages between participants who joined and who did not join the second wave of data collection (i.e. $23 \%$ vs $47 \%$ were male, respectively). There was also a significant difference of the percentages of having religious beliefs between participants who joined and who did not join the second wave of data collection (i.e. $34 \%$ vs $15 \%$, respectively). Therefore, in order to avoid biased conclusions, gender and religion would be taken as covariates in the following statistical analyses.

Computation of all variables was performed with the SPSS for Windows (version 10.0, SPSS, Chicago, IL, USA). The manipulation effects were checked by a dependent $t$-test. Then, the authors used a $2 \times 2$ ANCOVA to examine the main effects and the interaction effect of the two psychoeducation programs on help-seeking willingness.

\section{RESULTS}

First, the authors examined the manipulation effects of biological education and destigmatization education by a dependent $t$-test. The initial BAS and PBS scores (abbreviated as $\mathrm{BAS}_{\mathrm{T} 1}$ and $\mathrm{PBS}_{\mathrm{T} 1}$, respectively, hereafter) were subtracted from the BAS and PBS scores collected 2 weeks later (abbreviated as $\mathrm{BAS}_{\mathrm{T} 2}$ and $\mathrm{PBS}_{\mathrm{T} 2}$, respectively, hereafter). The manipulative effects of biological information $(t=8.54, P<0.001)$ and destigmatization information $(t=-3.11, P<0.01)$ were both approved, even though the effect of the latter was slightly weaker.

Next, using ANCOVA, the authors took initial HSWS (abbreviated as $\mathrm{HSWS}_{\mathrm{T} 1}$, hereafter), gender, and religion as covariates, and the HSWS taken 2 weeks later (abbreviated as $\mathrm{HSWS}_{\mathrm{T} 2}$, hereafter) as the dependent variable, to examine the effects of the two psychoeducation programs. The mean and standard deviations of the $\mathrm{HSWS}_{\mathrm{T} 2}$ were presented in Table 1. It was found that biological education had a main effect on increasing people's willingness to seek professional help ( $F[1$, $236]=5.65, P<0.02)$, but destigmatization education did not $(F[1,236]=0.44)$. In addition, no interaction effect was found between the two approaches ( $F[1$, $236]=0.42$; Fig. 1).

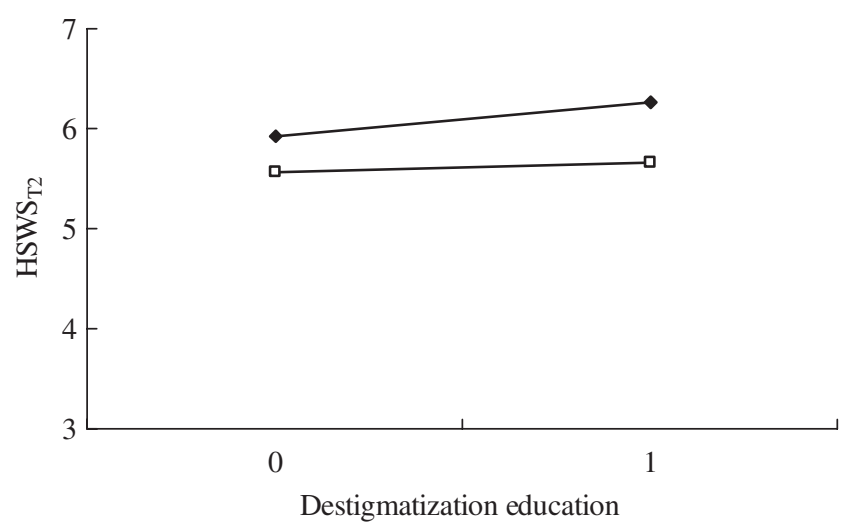

Figure 1. Significant main effect of biological education. ( $)$ Received biological education (1); ( $\square$ ) did not receive biological education (0). $\mathrm{HSWS}_{\mathrm{T} 2}$, Help-Seeking Willingness Scale taken after 2 weeks.

Table 1. Help-Seeking Willingness Scale taken after 2 weeks in various groups

\begin{tabular}{lccrrr}
\hline \multirow{2}{*}{ Groups } & \multicolumn{2}{c}{ Psychoeducation } & & \\
& Biological education & Destigmatization education & $n$ & Mean & SD \\
\hline Control group & 0 & 0 & 62 & 5.56 & 2.30 \\
Destigmatization group & 0 & 1 & 56 & 5.66 & 2.30 \\
& & Total & 118 & 5.61 & 2.29 \\
Biological group & 1 & 0 & 64 & 5.93 & 2.11 \\
Mixed group & 1 & 1 & 61 & 6.27 & 2.24 \\
& & Total & 125 & 6.10 & 2.17 \\
\hline
\end{tabular}




\section{DISCUSSION}

The goals of the present study were to use a quasiexperimental design to investigate the causal relationship between attribution of depression and willingness to seek professional help. The main findings included that increasing the belief of biological attribution enhances the willingness to seek help, but decreasing the blameworthy attitude towards depression does not; and no interaction exists between the two approaches.

It is noteworthy that, based on the manipulation of the present study, the evidence-based biological information that took only 5-10 min to comprehend could change attribution of depression significantly. It is, therefore, suggested that similar flyers designed to modify people's attribution for depression can be successfully used in the community. At least, evidencebased mental health education is suitable for people who have college level education. Similarly, the destigmatization manipulation that took only 5-10 min significantly changed attribution of depression as well. The result is consistent with the findings from the study of Corrigan et al. that the stigma of mental diseases could be reduced under proper education. ${ }^{19}$ In sum, the information manipulated in both kinds of education did bring out with expected effects, that is, increase of biological attribution $(t=8.54)$ and decrease of stigmatization $(t=-3.11)$.

Interestingly, according to findings of the present study, it appeared that biological education had a more significant effect than destigmatization education on the changes of attribution. In further scrutinizing the contents of the two programs, the authors found that biological information seems to be more concrete, empiric, and authoritative than that of destigmatization information. For example, biological education provided empiric data like the concentration of cortisol and the concordance rate in relatives. However, most information in destigmatization education that was just derived from psychological theories or clinical observations appeared to be more abstract and less effectual. In other words, although destigmatization information was cited to convince people that the causes of depression were neither the lack of willpower nor lack of ability, they seemed to be not as persuasive as biological information. Prior to the experiment, the authors had struck a balance between the bits of information of the two kinds of education in the hope to ensure equal effects, but the manipulation effect of destigmatization was weaker in the end. In fact, many empiric researches have evidenced the biological sources of depression, ${ }^{20}$ but few empiric studies have concluded that whether a depressive disorder was resulted from negative psychological traits of the depressed. Therefore, if more persuasive destigmatization information could be adopted in education in the future, a more remarkable decrease in the blameworthy attitude towards depression would be expected.

The findings of the present study showed that even though destigmatization education decreased people's negative attitude towards depressed people, it was not enough to lead people to adopt a new attribution of depression and then to increase their willingness to seek professional help. Many studies suggested that stigma is one important reason that obstructs helpseeking. For example, Asians tended to underutilize mental health services owing to the stigma of mental diseases ${ }^{21}$ and the more stigma felt by college students in Taiwan, the less willingness to seek professional counseling. ${ }^{22}$ With regards to the effects of stigma, it may vary in accordance with its target. The object of destigmatization education in the present study was to decrease stigma towards depressive individuals (others), but the stigma that has been reported as an effective factor for help-seeking was towards themselves. ${ }^{23,24}$ The target of stigmatization could be the essence that implements its influences variously. This may, therefore, explain why destigmatization education in the present study did not enhance help-seeking willingness as expected.

Biological education not only increases biological attribution of depression, but also leads people to seek help from mental health services. Consistent with the findings of association between biological attribution and help-seeking willingness reported by Goldstein and Rosselli, ${ }^{13}$ the authors further demonstrated the causal relationship of the two variables. In an anthropological field study conducted in Taiwan, Chang pointed out that treatment-seeking behavior would be generated only when people claimed a physically uncomfortable state as a symptom of illness. ${ }^{25}$ Using such an analog, it is inferred that help-seeking behavior for depression can be generated when psychological distress is first recognized as a symptom of mental disorders. In addition, biological attribution may help people legitimize such a depressive symptom, ${ }^{26}$ so that they would seek professional help. Future verification of the above-mentioned speculation is needed.

There were some limitations of the study. The sample was composed of college students and more were female, so that results might not be applicable to depressive individuals or the general public. Due to the differences of educational levels, the effects of evidence-based biological education for community residents might not be as good as that for undergraduate students. In addition, help-seeking willingness that in essence is an attitude, would not necessarily predict real help-seeking behavior. Questionnaires with higher 
reliability and validity may be still needed to ensure the stability of the findings. Last, despite the positive influence of biological attribution on help-seeking, it is still uncertain whether biological education would bring in any negative effect like reducing empowerment of the depressed people, or giving the impression that depressive disorders can neither be curable or avoidable. Intriguingly, it has been found that the more people attribute depression to biological factors, the stronger preference of psychotherapy as their choice of treatment, and the less people blame depressed individuals. ${ }^{13}$ All in all, to clarify the role biological attribution plays in the prevention of depressive disorders, future studies incorporating above-mentioned aspects with a better design should be in order.

Regardless of such shortcomings of the study, there are still important clinical implications for mental health promotion. First, destigmatization education could be applied to decrease people's negative appraisals of the depressive individuals, albeit it does not achieve the goal to increase people's willingness to seek professional help. Second, as knowledge of mental health is still not prevalent enough in many regions all over the world, it could be a proper strategy to lay stress on the biological etiology of depression, especially in the societies that emphasize emotional constraints. Biological education could help people to pay more attention to their depressive symptoms and then seek adequate treatment earlier, so that the course of depressive disorders would be shortened and the negativity surrounding depressed people would be lessened.

\section{ACKNOWLEDGMENT}

The authors gratefully acknowledge the help of Dr Tim Han, Center of General Education, National Taipei College of Nursing, Taipei, Taiwan, for data collection.

\section{REFERENCES}

1. Murray CJ, Lopez AD. The Global Burden of Disease. Harvard University Press, Cambridge, MA, 1996.

2. Goldapple K, Segal Z, Garson C et al. Modulation of cortical-limbic pathways in major depression: treatmentspecific effects of cognitive behavior therapy. Arch. Gen. Psychiatry 2004; 61: 24-41.

3. Robinson L, Berman J, Neimeyer R. Psychotherapy for the treatment of depression: a comprehensive review of controlled outcome research. Psychol. Bull. 1990; 108: 30-49.

4. Kessler RC, McGonagle KA, Zhao S et al. Lifetime and twelve-month prevalence of DSM-III-R psychiatric disorders in the United States: results from the National Comorbidity Study. Arch. Gen. Psychiatry 1994; 61: 8-19.
5. Yeung A, Chang D, Gresham RL, Nierenberg AA, Fava M. Illness beliefs of depressed Chinese American patients in primary care. J. Nerv. Ment. Dis. 2004; 192: 324-327.

6. Tsai M, Teng LN, Sue S. The mental health of the Chinese-Americans. In: Kleinman A, Lin TY (eds). Normal and Abnormal Behaviour in Chinese Culture. D. Reidel, London, 1981; 211-232.

7. Sue S, Sue DW. MMPI comparisons between AsianAmerican and non-Asian students utilizing a student health psychiatric clinic. J. Couns. Psychol. 1974; 21: 423427.

8. Sue S, Fujino DC, Hu L-T, Takeuchi DT, Zane NWS. Community mental health services for ethnic minority groups: a test of the cultural responsiveness hypothesis. $J$. Consult. Clin. Psychol. 1991; 59: 533-540.

9. Barry D, Grilo C. Cultural, psychological, and demographic correlates of willingness to use psychological services among East Asian immigrants. J. Nerv. Ment. Dis. 2002; 190: 32-39.

10. Tata SP, Leong FTL. Individualism-collectivism, socialnetwork orientation, and acculturation as predictors of attitudes toward seeking professional psychological help among Chinese Americans. J. Couns. Psychol. 1994; 41: 280-287.

11. Ying YW. Explanatory models of major depression and implications for help-seeking among immigrant ChineseAmerican women. Cult. Med. Psychiatry 1990; 14: 393 408.

12. Narikiyo TA, Kameoka VA. Attributions of mental illness and judgments about help seeking among JapaneseAmerican and white American students. J. Couns. Psychol. 1992; 39: 363-369.

13. Goldstein B, Rosselli F. Etiological paradigms of depression: the relationship between perceived causes, empowerment, treatment preferences, and stigma. J. Ment. Health 2003; 12: 551-563.

14. Halter MJ. Stigma and help-seeking related to depression: a study of nursing students. J. Psychosoc. Nurs. 2004; 42: 43-51.

15. Jorm AF, Griffiths KM, Christensen H, Korten AE, Parslow RA, Rodgers B. Providing information about the effectiveness of treatment options to depressed people in the community: a randomized controlled trial of effects on mental health literacy, help-seeking and symptoms. Psychol. Med. 2003; 33: 1071-1079.

16. Davison GC, Neale JM. Abnormal Psychology, 7th edn. John Wiley \& Sons, New York, 1997.

17. Kaplan HI, Sadock BJ. Synopsis of Psychiatry, 8th edn. Williams \& Wilkins, Baltimore, 1998.

18. Alloy LB, Abramson LY. Judgment of contingency in depressed and nondepressed students: sadder but wiser? J. Exp. Psychol. Gen. 1979; 108: 441-485.

19. Corrigan PW, River LP, Lundin RK et al. Three strategies for changing attributions about severe mental illness. Schizophr. Bull. 2001; 27: 187-195.

20. Thase ME, Jindal R, Howland RH. Biological aspects of depression. In: Gotlib IH, Hammen CL (eds). Handbook 
of Depression. .Guilford Press, New York, NY, 2002; 192-218.

21. Cheung FK, Snowden LR. Community mental health and ethnic minority populations. Community Ment. Health J. 1990; 26: 277-291.

22. Cheng LL. The exploring of psychological help-seeking process of Taiwan college students. Chinese J. Ment. Health 1987; 3: 125-138 (in Chinese).

23. Corrigan PW, Lundin RK. Don't Call Me Nuts: Coping with the Stigma of Mental Illness. Recovery Press, Tinley Park, Ill, 2001.
24. Yen CF, Chen CC, Lee Y, Tang TC, Yen JY, Ko CH. Self-stigma and its correlates among outpatients with depressive disorders. Psychiatr. Serv. 2005; 56: 599-601.

25. Chang $\mathrm{H}$. The medical systems and medical behaviors of the Han people in Taiwan. Illness and culture. DaoXiang, Taipei, 1989 (in Chinese).

26. Gammel DJ, Stoppard JM. Women's experience of treatment of depression: medicalization or empowerment? Can. Psychol. 1999; 40: 112-128. 